\title{
Elastography findings of encapsulated solid papillary carcinoma of breast in a man
}

\author{
Işıl Başara Akın¹, Hakan Abdullah Özgül1, Duygu Gürel², Süleyman Özkan Aksoy³, Pınar \\ Balci $^{1}$
}

${ }^{1}$ Department of Radiology, ${ }^{2}$ Department of Pathology, ${ }^{3}$ Department of General Surgery, Dokuz Eylul University School of Medicine

\begin{abstract}
Encapsulated solid papillary carcinoma (ESPC) is one of the malignant papillary lesions and classified it as ductal carcinoma in situ. Radiologic features of ESPC have been reported in the literature many times. However, to our best knowledge US elastography findings of ESPC have not been reported in the published literature yet. In this case report, we present US elastography findings of ESPC.
\end{abstract}

Keywords: elastography; breast; solid papillary carcinoma; men

\section{Introduction}

Breast papillary lesions are a group of lesions consisting of different lesions changing from benign to malignant $[1,2]$. One of the malignant papillary lesions is encapsulated solid papillary carcinoma (ESPC) [3], a low-grade tumor which originates from dilated ducts $[2,4]$ and defined as neuroendocrine differentiation showing endocrine ductal carcinoma in situ [4]. Additionally, the World Health Organization (WHO) classified this tumor as a ductal carcinoma in situ (DCIS). Less than 1\% of breast carcinomas are ESPCs [3]. It is usually more

Received 01.02.2019 Accepted 31.03.2019

Med Ultrason

2019, Vol. 21, No 4, 491-493

Corresponding author: Işı1 Başara Akın, MD

Department of Radiology, Dokuz Eylul

University School of Medicine

İnciraltı District, Mithatpaşa Street, no: 56 ,

35340, Balçova, İzmir, Turkey

E mail: slbasara@yahoo.com

Phone: +905066913699 common in elderly women than men [2,4]. Radiologic features of ESPC have been reported in the literature many times [5-8]. However, to our best knowledge, ultrasound (US) elastography findings of ESPC have not been reported yet.

We present the imaging evidence of ESPC diagnosed in a man, which is the first case presented in the literature in terms of US elastography.

\section{Case report}

A 72-year-old man with a palpable right breast mass since 6 months was evaluated at a general surgery outpatient clinic. A painless, mobile lesion at the retroareolar region of the breast was found and the patient was redirected to the breast imaging section for further evaluation.

Mammography (MG) detected a well-defined, circumscribed shaped, radiopaque, nodular lesion with the epicenter of retroareolar region in MG (fig 1a). US showed a $4 \mathrm{~cm}$ circumscribed shaped lesion with promi- 


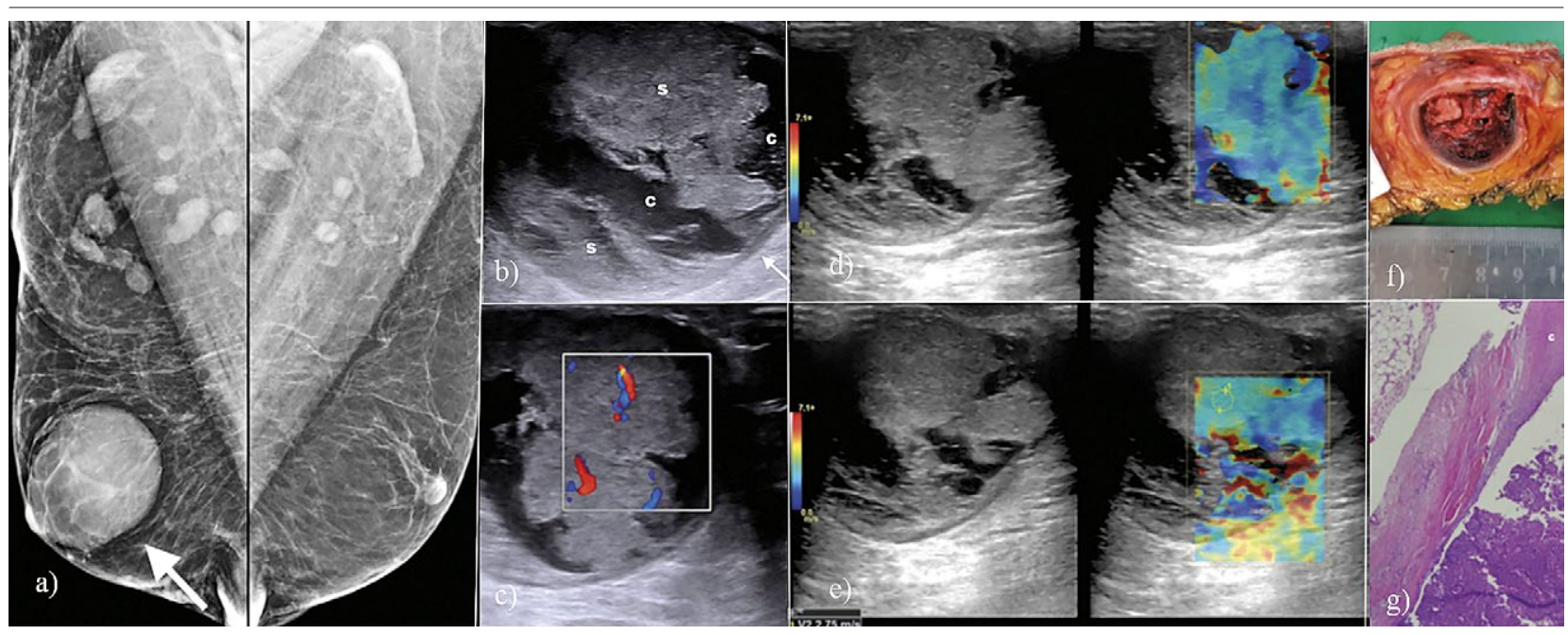

Fig 1. a) Bilateral mediolateral oblique mammography: a well-defined, circumscribed shaped, radiopaque, nodular lesion retroareolar region of right breast (arrow); b) B-mod ultrasonography: the lesion was circumscribed and measured $4 \mathrm{~cm}$. It was a complex lesion showing cystic [c] and solid components [s] with a prominent and regular capsule (arrow); c) Doppler ultrasonography: arterial blood flow is seen at the solid component of the lesion; d) Strain elastography: Ueno score was evaluated as score 2 with blue colored some areas compatible with low or no strain; e) Shear wave elastography: the elasticity score is measured as $2.75 \mathrm{~m} / \mathrm{s}-16.6 \mathrm{kPa}$; f) Macroscopic section of mastectomy material: the weight of the mass is $250 \mathrm{mg}$ with the diameter of $4.5 \mathrm{~cm}$. There is an encapsulated solid-cystic tumor with, subcutaneous-skin tissues and areola; g) Microscopic image: monomorphic, neoplastic epithelial cells with low nuclear degree surround fibrovascular roof. Additionally there is a thick fibrous capsule [c]. There is no myoepithelial cell around the papillary core (H\&E, x10, original magnification).

nent capsule and regular borders (fig $1 \mathrm{~b})$. The lesion was complex,with cystic and solid components and moderate vascularization (fig 1c)

In strain US elastography evaluation, Ueno score was evaluated as 2 and in shearwave elastography, the highest elasticity value in the lesion was $2.75 \mathrm{~m} / \mathrm{s}(16.6 \mathrm{kPa})$ (fig 1d,e). The lesion was interpreted as having intermediate malignant potential. But, taking in consideration the result of B-mode and Doppler US findings, the lesion was diagnosed as a malignant lesion, with pre-diagnosis ESPC, and categorized as Breast Imaging and Data System (BIRADS) 5. Thereafter, a US guided core needle biopsy was performed and the histological results confirmed our suspicion of ESPC.

The patient was redirected to excisional surgery for a total mastectomy and final pathologic diagnosis was ESPC without invasion (fig 1f,g). Estrogen and progesterone receptors were positive, Cerb-B2, HMWK, Calponin and $\mathrm{p} 63$ were negative.

\section{Discussions}

ESPC is a rare malignant breast tumor. The incidence is $1-2 \%$ in the general population [9]. Although it is more common in elderly women, most of male breast cancers are ESPC $[10,11]$. These tumors are well-defined including cystic components and hemorrhagic elements. ESCP usually presents with palpable, painless mass with or without nipple discharge [12].

In US elastography, malignant breast lesions are stiffer than benign tumors. These features of the lesions increase the specificity of US elastography in discrimination of the lesion [13]. In the literature 2-3.065 m/s and $70-80.17 \mathrm{kPa}$ are considered the threshold values in discrimination between benign and malignant tumors $[14,15]$.

There are false-positive and false-negative results of US elastography depending on the application technique, breast tissue thickness, the structure of surrounded tissue, lesion size and histologic features [16]. Malignant lesions with soft tissue structure, DCIS, mucinous carcinoma and necrotic tumors have less stiffness than other malignant tumors. In our case, although it was a malignant lesion, it had benign lesion characteristic evidencing a low Ueno Score with Score 2 and low strain value with $2.75 \mathrm{~m} / \mathrm{s}, 16.6 \mathrm{kPa}$. In our opinion, these false-negative findings depend on soft cystic components surrounding solid parts of the tumor, a non-invasive pattern meaning no infiltration into the surrounding tissue. Additionally, WHO classified ESPC as DCIS and DCIS has frequently false-negative US elastography findings.

We presented a case of ESPC in a man. Conventional radiologic features of ESPC, including MG, US and color Doppler US have been reported in the literature and 
are well-known but US elastography findings of ESPC have not been described.

In conclusion, although ESPC is accepted as DCIS, it is a malignant lesion and needs to be total excised surgically. However, US elastography of ESPC could have benign features with false-positive imaging findings. US elastography provides a prominent contribution in the discrimination of benign and malignant lesions; in the radiologic diagnosis of ESPC, conventional radiologic features should be considered in the first stage.

\section{References}

1. Zhong DR, Sun PP, Liang ZY. Clinicopathological features of solid papillary carcinoma in breast. J Diag Path 2010;17:165-168.

2. Rakha EA, Ahmed MA, Ellis IO. Papillary carcinoma of the breast: diagnostic agreement and management implications. Histopathology 2016;69:862-870.

3. Tan PH, Schnitt SJ, van de Vijver MJ, Ellis IO, Lakhani SR. Papillary and neuroendocrine breast lesions: the WHO Stance. Histopathology 2015;66:761-770.

4. Saremian J, Rosa M. Solid papillary carcinoma of the breast: a pathologically and clinically distinct breast tumour. Arch Pathol Lab Med 2012;136:1308-1311.

5. S H, Hariprasad P, Srinivas T. Intracystic papillary carcinoma of the breast in males: a case report and review of the literature. J Clin Diagn Res 2013;7:568-570.

6. Johnson JB, Emory TH. Intracystic Papillary Carcinoma in a Man with Gynecomastia. Radiol Case Rep 2015;3:214.

7. Blaumeiser B, Tjalma WA, Verslegers I, De Schepper AM, Buytaert P. Invasive papillary carcinoma of the male breast. Eur Radiol 2002;12:2207-2210.
8. Y1lmaz R, Cömert RG, Aliyev S, et al. Encapsulated Papillary Carcinoma in A Man with Gynecomastia: Ultrasonography, Mammography and Magnetic Resonance Imaging Features with Pathologic Correlation. Eur J Breast Health 2018;14:127-131.

9. Soo MS, Williford EM, Walsh R, Bentely CR, Kornguth JP. Papillary carcinoma of the breast: imaging findings. AJR Am J Roentgenol 1995;164:321-326.

10. Fisher ER, Palekar AS, Redmond C, Barton B, Fisher B. Pathologic findings from the National Surgical Adjuvant Breast Project (Protocol No. 4). VI. Invasive papillary cancer. Am J Clin Pathol 1980;73:313322.

11. Rosen PP. Carcinoma of the Male Breast. In: Hoda SA, Brogi E, Koerner FC, Rosen PP (eds). Rosen's Breast Pathology, 2nd edition, Lippincott Williams \& Wilkins, 2001:713-728.

12. Akagi T, Kinoshita T, Shien T, Hojo T, Akashi-Tanaka S, Murata Y. Clinical and pathological features of intracystic papillary carcinoma of the breast. Surg Today 2009;39: 5-8.

13. Schaefer FK, Heer I, Schaefer PJ, et al. Breast ultrasound elastography: results of 193 breast lesions in a prospective study with histopathologic correlation. Eur J Radiol 2011;77:450-456.

14. Balleyguier C, Ciolovan L, Ammari S, et al. Breast elastography: the technical process and its applications. Diagn Interv Imaging 2013;94:503-513.

15. Barr RG. Sonographic breast elastography: a primer. J U1trasound Med 2012;31:773-783.

16. Chang JM, Moon WK, Cho N, Kim SJ. Breast mass evaluation: factors influencing the quality of US elastography. Radiology 2011;259:59-64. 